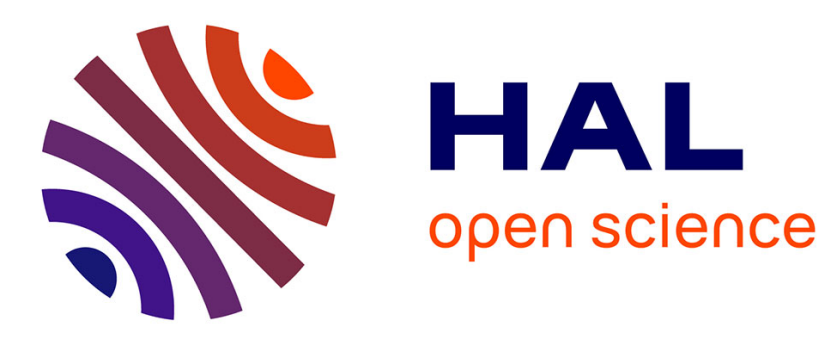

\title{
Numerical modelling of geothermal vertical heat exchangers for the short time analysis using the state model size reduction technique
}

Eui-Jong Kim, Jean-Jacques Roux, Gilles Rusaouen, Frédéric Kuznik

\section{- To cite this version:}

Eui-Jong Kim, Jean-Jacques Roux, Gilles Rusaouen, Frédéric Kuznik. Numerical modelling of geothermal vertical heat exchangers for the short time analysis using the state model size reduction technique. Applied Thermal Engineering, 2009, 30 (6-7), pp.706. 10.1016/j.applthermaleng.2009.11.019 . hal00579483

\section{HAL Id: hal-00579483 \\ https://hal.science/hal-00579483}

Submitted on 24 Mar 2011

HAL is a multi-disciplinary open access archive for the deposit and dissemination of scientific research documents, whether they are published or not. The documents may come from teaching and research institutions in France or abroad, or from public or private research centers.
L'archive ouverte pluridisciplinaire HAL, est destinée au dépôt et à la diffusion de documents scientifiques de niveau recherche, publiés ou non, émanant des établissements d'enseignement et de recherche français ou étrangers, des laboratoires publics ou privés. 


\section{Accepted Manuscript}

Numerical modelling of geothermal vertical heat exchangers for the short time analysis using the state model size reduction technique

Eui-Jong KIM, Jean-Jacques Roux, Gilles Rusaouen, Frédéric Kuznik

PII:

S1359-4311(09)00347-0

DOI:

10.1016/j.applthermaleng.2009.11.019

Reference:

ATE 2937

To appear in:

Applied Thermal Engineering

\section{APPLIED}

THERMAL

ENGINEERING

12 August 2009

Accepted Date:

27 November 2009

Please cite this article as: E-J. KIM, J-J. Roux, G. Rusaouen, F. Kuznik, Numerical modelling of geothermal vertical heat exchangers for the short time analysis using the state model size reduction technique, Applied Thermal Engineering (2009), doi: 10.1016/j.applthermaleng.2009.11.019

This is a PDF file of an unedited manuscript that has been accepted for publication. As a service to our customers we are providing this early version of the manuscript. The manuscript will undergo copyediting, typesetting, and review of the resulting proof before it is published in its final form. Please note that during the production process errors may be discovered which could affect the content, and all legal disclaimers that apply to the journal pertain. 


\title{
Numerical modelling of geothermal vertical heat exchangers for the short time analysis using the state model size reduction technique
}

\section{Eui-Jong KIM ${ }^{\text {a, b }}$, Jean-Jacques ROUX a , Gilles RUSAOUEN ${ }^{\text {a }}$, Frédéric KUZNIK ${ }^{\text {a }}$}

\author{
${ }^{a}$ Université de Lyon, CNRS
}

INSA-Lyon, CETHIL, UMR5008, F-69621, Villeurbanne, France

Université Lyon 1, F-69622, France

${ }^{\mathrm{b}}$ Research and Development Division, Electricité de France (EDF), Les Renardières - 77818

Moret sur Loing, France

\begin{abstract}
According to the introduction of a dynamic operating mode in ground-coupled heat pump systems, a short time analysis within and around borehole heat exchangers is required in the modern geothermal system simulation. A numerical modelling could be a proper answer for this challenge. However, the numerical model is time consuming and necessitates a large memory particularly in such large systems. Therefore, the state model size reduction technique has been applied in this paper with various numerical techniques particularly in the finite elements method. As a result, the reduced model developed is: a) relevant with a validation using a traditional analytical model (using 100\% modes) and b) efficient in calculation time, only using $6 \%$ modes and consequently reducing time consumption up to $95 \%$.
\end{abstract}

Keywords: borehole heat exchanger; numerical simulation; state model size reduction; short time analysis; FEM

\footnotetext{
* Corresponding author. Tel.: +33-472-438-461; fax: +33-472-438-522.

E-mail address: frederic.kuznik@insa-lyon.fr (F. Kuznik).
} 


\section{Introduction}

Since many years, the installation of ground-coupled heat pump (GCHP) in buildings has increased because of their efficiency for heating and cooling. Contrary to this aspect, the relatively higher initial cost of geothermal vertical heat exchangers, or called borehole heat exchangers (BHE) would have been an obstacle to the spread of the systems particularly in the residential buildings.

On the other hand, a combination of the GCHP with solar thermal collectors has been studied in recent years, for example the direct thermal recharge of the soil through the same $U$ tubes using the solar collector [1]. Chiasson [2] showed in his simulation analysis that the combination system makes possible to reduce BHE length. A dynamic operating mode being introduced in such system, a short time analysis within and around the borehole is required for understanding heat transfer having characteristic time of one hour or even few minutes.

In order to give an appropriate response to this challenge, several models have already been developed, based on analytical or numerical solutions. Lamarche et al. [3] proposed a model which is capable to analytically take into account the effect of inertia of the borehole for the short time analysis. In spite of their exactness under the given conditions, the developed analytical models cannot be easily used for any conditions. Moreover, many coefficients used in the analytical model can only be obtained a posteriori using a numerical model or experimental data. Despite everything, numerical analyses for this purpose have been continuously developed, for example the work of Yavuzturk et al. [4] which was considered as the one of the first numerical approach modelling geothermal vertical boreholes, i.e. the pipes and the grout with their inertia. More recently, Cui [5] compared his FEM (Finite Element Method) to the traditional analytical model, in the case of the infinite line source [6]. 
The results prove the importance of the short time analysis particularly in an alternative operating schedule. Although the FEM numerical method is accurate, the relatively large calculation time and the large memory required are its shortcomings for an application in such large system especially in the case of a long period simulation (typically a year for building application after many-year-operation of the system).

Therefore, in this paper, we propose a numerical model for short time transient response, using a state model size reduction technique for decreasing the calculation time. The part 2 of the paper details the model size reduction technique. The numerical model is presented in the third part of the article and the fourth part deals with the modelling strategies. The part 5 presents the results of the numerical simulations showing the method efficiency.

\section{State model size reduction technique}

For thermal analysis, model size reduction techniques have been used for different purposes over the last 30 years since its invention [7] in the field of automatic controls. Among them, several transient analyses of large systems found in heavy building components have been studied. For example, Mokhtari [8] studied the thermal interaction between the building floor and the surrounding soil; Gao et al. [9] proposed a model for the thermal bridge in the wall corner with a 3D approach. Then, we will use the model size reduction technique whose implementation process will be described in the following parts.

\subsection{State space model}

Above all, some assumptions are supposed for our mathematical modelling as follows:

- The soil property $(\lambda, \rho, c)$ is considered constant; consequently, $\alpha$ constant

- The heat transfer is considered 2-dimensional in the Cartesian 
- The perfect thermal contact between the materials is supposed

Therefore, the heat equation can be expressed as:

$$
\frac{\partial}{\partial t} T_{0}(x, y, t)=\alpha\left(\frac{\partial^{2} T_{0}}{\partial x^{2}}+\frac{\partial^{2} T_{0}}{\partial y^{2}}\right)
$$

For numerical analysis, the continuous problem must be converted into an algebraic problem. Then, the spatial discretization of Equation 1 using finite volume method (FVM) or finite element method (FEM) leads to the following linear equation system:

$$
\dot{T}(t)=C^{-1} A T(t)+C^{-1} B^{\prime} U(t)
$$

Where $T(t)$, the approximated state vector (dimension: $\mathrm{n}, 1$ ), is the assembly of the time dependant nodes temperature of the system, that is, $T(t)$ contains all the nodes temperatures which locations are defined by the spatial discretization : $T(t)=\left\{T_{1}(t), T_{2}(t), T_{3}(t), \ldots T_{n}(t)\right\}$, where $1,2,3 \ldots n$ indicate the node number order in the mesh generation. The matrix $C$, the square capacitance matrix (dimension: $n, n$ ), is related to the thermal inertia of the finite volumes, and the matrix $A$, the square conductance matrix, contains thermal relations among the nodes represented by the state vector $T(t) . U(t)$, the solicitation vector (dimension: $\mathrm{p}, 1$ ), represents the boundary conditions of the system, therefore; the matrix $B^{\prime}$, a rectangular matrix (dimension: $\mathrm{n}, \mathrm{p}$ ), represents physical relation between the boundary conditions and the system.

In dynamic simulations, only the evolution of some particular values is necessary: for example, temperatures or heat flux in specific boundaries. For these values, another state model could be defined as:

$Y(t)=J T(t)+D U(t)(3)$

The output vector $Y(t)$ (dimension: q, 1) is the assembly of the concerning outputs, $J$, the observation matrix (dimension: $\mathrm{q}, \mathrm{n}$ ) and $D$, the direct transmission matrix (dimension: $\mathrm{q}, \mathrm{p}$ ) 
are defined under the physical correlation with the state vector and the solicitation vector, respectively.

The state model mentioned above is a complete expression for the dynamic simulation. However, the numerical approach for the fine analysis of such large system is always calculation time consuming. Therefore, the state model size reduction technique is naturally expected, and then the reduction processes is be described in the following part.

\subsection{Reduction technique}

The objective of the state model size reduction technique is to reduce the order of the abovedescribed state space model $(m<<n)$ (see equation 2-3) and then the calculation time. There are several approaches already developed for various purposes, so we will only present the method used in this paper, demonstrating a common philosophy concerning the category (modal basis truncation) to which our method belongs. The different categorizations were proposed by Petit [10].

Above all, a basis change into the modal basis has to be accomplished ahead of the reduction processes because the new model reproduced in the modal basis could be truncated. The modal basis model could be obtained by the diagonalization of the matrix $C^{-1} A$ (2). Consequently, the modal basis model and its correlations from the equations (4) and (5) can be written as:

$\left\{\begin{array}{l}\dot{X}(t)=W X(t)+B U(t) \\ Y(t)=\Omega X(t)+D U(t)\end{array}\right.$

$T(t)=P X(t), \quad W=P^{-1} C^{-1} A P, \quad B=P^{-1} C^{-1} B^{\prime}, \quad \Omega=J P$

The modal state $X(t)$ indicates an assembly of modes of the system which related the dynamic evolution of the system, and each element of the diagonal matrix $W$ corresponds to an 
eigenvalue $\xi_{i}$ of the initial matrix $C^{-1} A: W=\operatorname{diag}\left(\lambda_{i}\right)$, and the associated eigenvectors $V_{i}$ compose the matrix $P: P=\left[V_{1} V_{2} \ldots . . V_{i} \ldots V_{n}\right]$.

Then, various reduction methods for Equation 4 can be used. Marshall [7] firstly proposed a method for choosing the dominant modes, i.e. the critical modes for deciding the dynamic evolution of the outputs $(Y(t))$. He introduced a temporal criterion in order to select the modes that are the most meaningful for the dynamic analysis: $\tau_{i}=\left|\xi_{i}^{-1}\right|>\Delta t / 4$ with $\Delta t$ the time step used in the numerical simulation. The rest modes could be used only for the constitution of the steady state condition. This method is simple but inefficient for the common purpose of truncating most of the non-dominant modes. Another method often used in the building thermal analysis is the linear aggregation method. This method uses the notion of energy contribution whose matrix terms are defined by the relation (6). The criterion for selecting the dominant modes, i.e. the most energetic modes, is: $\sum_{i=1}^{m} E_{i i} \cong \sum_{i=1}^{n} E_{i i}$ with $m$ the number of the dominant modes. The details about the construction of $E_{i j}$ are given in [11], where $r^{\prime}$ has 0 for Dirac impulse or 1 for Heaviside step function. In the truncation category, the method of Moore was developed by a slightly different approach that is detailed in [12].

$E_{i j}=-\frac{\sum_{l=1}^{q} \Omega_{l i} \Omega_{l j} \sum_{k=1}^{p} B_{i k} B_{j k}}{\left(\xi_{i} \xi_{j}\right)^{r^{\prime}}\left(\xi_{i}+\xi_{j}\right)}$

In the present study, the reduction uses the linear aggregation method but the final equations (7) would have the same structure for all the techniques briefly presented previously.

First, the unselected modes are removed from the initial equation (4) and, consequently, the state order can be reduced from $n$ to $m$ with $m<<n$. Therefore, $Y(t)$ could be obtained with approximated values $\tilde{Y}(t)$ but with faster calculation. The error due to this reduction processes could vary according to the chosen method and the error definition in the criterion... As we 
already mentioned, the non-dominant modes unselected just contribute to the accuracy of the calculated steady state (see the last term in each equation of (7)).

$$
\left\{\begin{array}{l}
\dot{X}_{m}(t)=W_{m} X_{m}(t)+G_{m} U(t), \quad X_{n-m}=-W_{n-m}{ }^{-1} G_{n-m} U(t) \\
\tilde{Y}(t)=\Omega_{m} X_{m}(t)+\left(D-\Omega_{n-m} W_{n-m}^{-1} G_{n-m}\right) U(t)
\end{array}\right.
$$

\section{Numerical model}

To implement the state model size reduction technique, a specific computer code has been written in spite of the availability of commercial simulation packages because the reduction procedure contains many matrix transformations. In the following parts, the numerical methods employed for the new code will be described.

\subsection{Unstructured mesh}

As mentioned in the introduction, a fine mesh should be used in this model for the exact short time response of the geothermal vertical boreholes. Many various meshes have been proposed like the structured mesh [4], [13] or the unstructured mesh [5], [14]. However, the structured mesh models could not describe the circular configuration found within the boreholes. For example, Rottmayer [13] proposed a geometric factor for reducing the errors caused by adopting the equivalent non circular shape. Moreover, the structured models developed in the polar grid system cannot be flexible for a multiple borehole simulation.

For these reasons, an unstructured mesh based on the Delaunay triangulation for the horizontal plan was adopted in the paper (see Figure 1). In this work, the mesh is generated by Gmsh [15]. The mesh generator outputs mesh information (i.e. a mesh file) so that the grid information could be integrated in our code with an additional identification procedure. 


\subsection{Finite elements method}

On the one hand, the unstructured mesh is a good solution because of the flexible mesh generation and consequently the possibility to obtain a lower mesh number in a complex configuration system. On the other hand, the non-orthogonal relationship caused by this unstructured mesh must be corrected, particularly when using FVM, which has been a common method in the conduction heat transfer analysis. However, the correction method, using, for example, the least-square approach [16], could make the conductance matrix $A$ (Equation 2) asymmetric. In addition, an approximation with FVM like average thermophysical properties between two different materials must be used in the correction formula although a special correction method would have been used for the symmetry of A. As a result, the FEM, a method free from these approximations by its nature, is applied in the model.

For FEM, the weak formulation of the governing equation (1) could be achieved by using some mathematical modification using a weighting function $T^{*}$. The obtained low-order Equation 8 is not handling the non orthogonal nature in the process of the matrices definition.

$$
\int_{V} T^{*} \rho c \frac{\partial}{\partial t} T \mathrm{dV}+\int_{V} \nabla T^{*} \lambda \nabla T \mathrm{dV}=0 \quad \forall T^{*}
$$

Ahead of transforming Equation 8 into the algebraic equation (Equation 2), an approximation of temperatures inside an element is supposed by an interpolation function (Equation 9-10). In this paper, all the expressions are described for the $2 \mathrm{D}$ triangulation mesh.

$$
T^{e}(x, y, t)=\left[N_{1}^{e}(x, y) N_{2}^{e}(x, y) N_{3}^{e}(x, y)\right]\left\{\begin{array}{l}
T_{1}^{e}(t) \\
T_{2}^{e}(t) \\
T_{3}^{e}(t)
\end{array}\right\}=\left[N^{e}(x, y)\right]\left\{T^{e}(t)\right\}
$$


$N_{i}(x, y)=\frac{a_{i}+b_{i} x+c_{i} y}{2 \Delta}$

Where, $a_{i}, b_{i}, c_{i}$ will be defined by the geometric information in each element, and $\Delta$ the area of the element considered.

For the temperature gradient, another function could be employed from $N_{i}$ formulation.

$[M]=\left[\begin{array}{lll}\frac{\partial N_{1}}{\partial x} & \frac{\partial N_{2}}{\partial x} & \frac{\partial N_{3}}{\partial x} \\ \frac{\partial N_{1}}{\partial y} & \frac{\partial N_{2}}{\partial y} & \frac{\partial N_{3}}{\partial y}\end{array}\right]=\frac{1}{2 \Delta}\left[\begin{array}{ccc}b_{1} & b_{2} & b_{3} \\ c_{1} & c_{2} & c_{3}\end{array}\right]$

From these approximations, the weak formulation (Equation 8) for the element could be expressed as Equation 12, adding a flux (W/m) boundary condition on pipe walls if the element belongs to a pipe wall mesh.

$\left\{T^{*}\right\}^{T}\left(\left[C^{e}\right]\left\{\dot{T}^{e}\right\}-\left[A^{e}\right]\left\{T^{e}\right\}-\left[B^{\prime e}\right]\left\{U^{e}\right\}\right)=0$

Because the weight function $T^{*}$ is an arbitrary function, only the right part of the equation 12 is required to be zero. The capacity matrix $C$, the conductance matrix $A$, and the matrix $B^{\prime}$ for the element considered could be expressed by a combination of the approximation functions $N$ and $M$ as:

$\left[C^{e}\right]=\int_{\Delta} \rho c[N]^{T}[N] d \Delta$

$\left[A^{e}\right]=-\int_{\Delta}[M]^{T}[\lambda][M] d \Delta$

$\left[B^{\prime e}\right]=-\int_{l}[N]^{T} d l$

For the triangulation mesh, the matrices (Equation 13 - 15) can also be expressed as:

$\left[C^{e}\right]=\frac{\rho c \Delta}{12}\left[\begin{array}{lll}2 & 1 & 1 \\ 1 & 2 & 1 \\ 1 & 1 & 2\end{array}\right]$ 


$$
\begin{aligned}
& {\left[A^{e}\right]=-\frac{\lambda}{4 \Delta}\left[\begin{array}{ccc}
b_{1}^{2}+c_{1}^{2} & b_{1} b_{2}+c_{1} c_{2} & b_{1} b_{3}+c_{1} c_{3} \\
b_{2} b_{1}+c_{2} c_{1} & b_{2}^{2}+c_{2}^{2} & b_{2} b_{3}+c_{2} c_{3} \\
b_{3} b_{1}+c_{3} c_{1} & b_{3} b_{2}+c_{3} c_{2} & b_{3}^{2}+c_{3}^{2}
\end{array}\right]} \\
& {\left[B^{\prime e}\right]=\frac{l}{2}\left\{\begin{array}{l}
1 \\
1
\end{array}\right\}}
\end{aligned}
$$

All these matrices (Equation 16-18) defined for each element in the considered domain have to be assembled by an element-by-element overlap (Equation 19) for completing the algebraic equation (Equation 2).

$\sum_{e}\left[C^{e}\right]=C, \sum_{e}\left[A^{e}\right]=A, \sum_{e}\left[B^{\prime e}\right]=B^{\prime}$

\section{Modelling strategies}

A complete BHE model could be developed with the methods defined in the previous sections. However, a naïve numerical approach is not desirable in terms of the calculation time and the occupying memory because of the presence of large size matrices. In fact, the required calculation time for an $n$-order matrix is generally in the order of $n^{3}$ and the necessary memory is increased by the same order. Accordingly, some modelling strategies are necessary. These strategies will be developed in the followings.

\subsection{Slice model}

In this paper, a novel slice model of the ground soil volume is introduced and accomplished by extruding a horizontal cross-section as shown in Fig 2. This slice model could be used for a complete model of the relatively long borehole simulation (case1): when $\alpha t \leq H^{2} / 100$ [17]. In addition, several uses of this pre-defining slice model are suitable for describing the fluid temperature variation with borehole depth (case 2). For the 3D simulation, accounting for the 
thermal interaction among the slice models, the model could be employed just by adding the temperatures of the adjacent models to the solicitation vectors $U$ (case 3). This strategy was motivated by the fact that each slice model has normally an identical mesh configuration, so that the definition of the corresponding matrices (Equations 2-5 and 7) for one slice model is sufficient for its multiple use and particularly for the reduced state model. In addition, the calculation time and the necessary memory are dramatically reduced if partial models are employed for the entire model: $a(N n)^{3}>>b N n^{3}$ where $N$ is the number of slice models and n, the number of nodes in a slice. In this article, only the 2-dimensional slice model (case 1 in Fig. 1) is treated as a complete model, and then this model results would be applied directly for the other applications (case 2-3).

\subsection{Decomposition of the slice in sub-zones}

Following the conclusion of the previous section, the model efficiency in calculation time is enhanced with the sub-zone decomposition of the model presented in Figure 3. In this paper, 4 sub-zone models were proposed, which cover packed soil regions respectively (see Figure 3-b). This method makes it possible to use different time steps for each sub-zone, which could generally be helpful for the time reduction. Additionally, this decomposition is indispensable to take advantage of the state model size reduction technique (see the section 5). The decomposition has also the benefit that, in the presence of multiple boreholes, the matrices definition and their modification for a borehole sub-zone could be reused for other boreholes sub-zones (see Figure 3-c).

In order to decompose the model, a coupling method must be applied to interconnect physical frontier values like temperatures and fluxes until each value converges in the given time step 
and for the domain considered. However, the nodes on the frontier mesh in the decomposed model have some information of the previously neighboring elements which are currently in the adjacent sub-zone model. Therefore, a special attention must be paid to conserve all the elements information, particularly in the nodes on a decomposition frontier when using decomposition in FEM. In brief, a new temperature boundary has been defined between the sub-zone models decomposed (see Figure 4). With the boundary, all elements information around the frontier nodes could be recovered with some matrices modifications. Then, these sub-zone models employ their own time steps, and then the boundary results in each sub-zone time step are interpolated or extrapolated by a linear function in order to well correspond with the adjacent sub-zones time step in the temporal coupling under the acceptable error criterion, and then keep the accuracy of the numerical scheme. Finally, all the spatial and temporal coupling is completed by an iterative calculation.

\subsection{Boundary conditions}

For the boundary conditions, flux is imposed at the exterior walls of pipes, and the upper and lower boundaries of the slice model are adiabatic (case 1 in Figure 2). The fluxes on each tube, each branch of U-tube, could be calculated iteratively by a coupling with a fluid model which will be not treated in this study but replaced by an imposed flux condition. The parameters and boundary conditions used for the simulations are presented in Table 1 and 2 respectively. Two cases of heat injection are tested: constant flux case for the steady state regime and long time analysis; sinusoidal flux case for the alternative operating analysis (Table 2). For the model size, a $100 \mathrm{~m}$ radius soil domain case is treated which is suitable for a long time simulation of about 20 years, according to the criterion of Eskilson [17]: $r_{\max }=3\left(\alpha t_{\max }\right)^{0.5}$. 


\section{Results and discussion}

\subsection{Mesh independency}

The mesh independency concerning simulation results is important for numerical solution because it will decide model relevance and lightness in terms of error and calculation time respectively. For this purpose, an error evaluation has been defined, based on the maximum temperature difference between the two compared models, and this evaluation (Equation 20) will be used for other simulation results in this paper.

Maximum error $=\max \left|\mathrm{T}_{\text {ref }}-\mathrm{T}_{\text {test }}\right|$

Figure 5 shows the result on the comparison of different mesh models for the mean borehole wall temperature when injecting constant heat. The first three mesh models $(n=1918,1406$, 1018) have the maximum error less than $0.1\left({ }^{\circ} \mathrm{C}\right)$, correspondent relative error $0.43 \%$, among them, which was comparatively smaller than other models ( $n=625$ and 313). Therefore, the mesh model whose order is $n=1018$ was selected as the reference simulation mesh model in this article. This mesh configuration is presented in Figure 6 and the correspondent mesh information in Table 3.

\subsection{Model validation}

In order to validate our approach and show the efficiency of the method proposed in this paper, the numerical model is compared to the analytical model of the infinite line source [6]. This test case has been chose because small errors for each time step in a numerical model could normally accumulate for long time analysis in the geothermal system. The figure 7 
shows the comparison between the analytical model and the numerical data which are in good agreement.

For detailed information, the relative error [21] is used to estimate the error between the two models:

Relative error $=\left|\frac{\text { Numerical value }- \text { Analytical value }}{\text { Numerical value }- \text { Initial value }}\right| \times 100 \%$

The figure 8 shows the evolution of the relative error. Some differences between the two models exist during the first period $\left(F_{O}=\alpha t / r_{b}{ }^{2}<20\right)$ but are normal because the infinite line source model is only valid if the time criterion $F o>20$ is satisfied [6].

When using this entire slice model, the reduction technique is not suitable because the spectra of eigenvalues in this case are very large. Then, the slice decomposition into multiple subzone models is mandatory in order to dense the spectra of eigenvalues which normally decide the system evolution characteristic in a dynamic analysis.

Before examining the sub-zone reduced model, the sub-zone models using the coupling method (spatial and temporal) has to be compared to the entire slice model. Fig 9 shows the temperature evolution on the borehole wall for the models examined. The results of the models are in good agreement. The maximum error of the spatial coupling was $0.00038\left({ }^{\circ} \mathrm{C}\right)$, and $0.078\left({ }^{\circ} \mathrm{C}\right)$ for the spatial and temporal coupling.

\subsection{Comparison between complete model and reduced model}

For the reduced model (RM) simulation, 4 sub-zones are used and each sub-zone has a different simulation time step: 1 hour, 6 hour, 1 day, and 1 week from the borehole to exterior respectively while the complete model $(\mathrm{CM})$ has only one time step (1hr) for all the sub-zones. The complete model $(\mathrm{CM})$ uses all of the system modes and is compared to the reduced 
model (RM) using the linear aggregation (LA) technique with $99 \%$ energy criterion: $\left(=\sum_{i=1}^{m} E_{i i} / \sum_{i=1}^{n} E_{i i} \times 100[\%]\right)$.

As shown in Figure 10, RM-LA model and CM are in good agreement with the maximum error of $0.31^{\circ} \mathrm{C}$. The selected modes ratio of RM-LA model to CM is about $6 \%(66<<1018)$ and, consequently the reduction in computational time is about $90 \%$. This efficiency could be explained by the result presented in figure 11. Each sub-zone model has an unambiguous energy distribution; that is, some primary modes might decide the dynamic evolution in the given time step, which did not appear in the original entire slice model.

Subsequently, a dynamic heat injection is studied for evaluating the validity of the modelling in the case of short time operation. The heat flux is supposed to be sinusoidal as explained in the boundary condition section. The figure 12 shows the pipe wall mean temperature evolution for CM and RM-LA models with different energy criteria in order to observe the energy criterion impact. Above all, the two models (CM and RM-LA 99\%) are in good agreement with a maximum error $0.274\left({ }^{\circ} \mathrm{C}\right)$. However, other models with 95 and $85 \%$ energy criteria have 1.29 and $2.40\left({ }^{\circ} \mathrm{C}\right)$ in maximum error respectively. Although the amount of the selected modes decreases according to the energy criterion, the amount of the selected modes is not greatly different among the reduced models. Furthermore, the CPU time for the transient calculation among the different reduced models was almost similar: in this case, $70 \%$ calculation time reduction is obtained compared to $\mathrm{CM}$ because of convergence problem in such a dynamic input. Therefore, using RM-LA 99\% could be a good solution in this decomposed slice model.

In order to further examine the RM precision compared to the $\mathrm{CM}$ and generalize the proven results, we use the bode diagrams. For this simulation, the output mean temperature on the pipe wall is observed when the input flux on the same wall is introduced in the borehole region. First of all, the result (see Figure 13) shows that the magnitude difference between 
$\mathrm{CM}$ and $\mathrm{RM}$ is almost zero for frequencies lower than $2 \times 10^{-2}$ which corresponds about $5 \mathrm{~min}$ excitation period. In terms of the phase difference, the two models have nearly the same response in the area lower than the frequency $2 \times 10^{-3}$. Although this frequency matches about 50min excitation period, this period level would be sufficient for application within geothermal system simulation field even for the short time analysis. Actually, a simulation with a time step $1 \mathrm{~min}$ with 10 min periodic input fluxes (between the frequencies $2 \times 10^{-2}$ and $2 \times 10^{-3}$ ) showed a good concordance between the CM and RM with a slight error less than the result of Figure 12. Additionally, when using one minute time step, the RM had the advantage that it reduces $95 \%$ of the transient calculation time compared to the CM. This efficiency gives a merit to the model developed (RM-LA) particularly in the short time analysis because this efficiency has decreased when the larger time step was applied (70\% time reduction in 1 hour time step).

\section{Conclusion}

A short time analysis is required in modern BHE simulation by the presence of dynamic operation modes in the order of an hour or even few minutes. For such an analysis it is necessary to take into account the inertia within and just around a borehole for describing the precise transient phenomena. In this context, a numerical model has been developed which could simulate the borehole configuration and would be calculation time efficient. Then, an unstructured mesh generator (Gmsh) has been used and various techniques have been employed: from a slice model via sub-zone structure to the use of reduced models. Particularly, the finite elements method and the use of different time steps in each sub-zone have been applied to implement the reduced technique. Moreover, a coupling method for FEM has been applied. 
The model has been validated using analytical solutions from the literature. The reduction in computational time in the reduced model was up to $95 \%$ compared to the complete model. The main interest of the developed model is that short time dynamic effects can be easily and rapidly simulated, allowing to significantly enhance the understanding of coupled boreholes systems.

The results can also be a complete reference for the short time analysis when coupling a fluid model for the sufficiently long vertical borehole. Another 3D model for the relatively short borehole is under development based on the slice model by multiplying the slices and adding some solicitation vectors to the slice matrices with newly defined boundary conditions like an ambient temperature on the soil surface.

\section{Acknowledgements}

The authors want to thank EDF (Electricity of France) R \& D for its financial, scientific, and technical support in the framework of the French support program CIFRE.

\section{References}

[1] V. Trillat-Berdal, B. Souyri, G. Fraisse, Experimental study of a ground-coupled heat pump combined with thermal solar collectors, Energy and Buildings 38 (2006) 1477-1484.

[2] A. Chiasson, C. Yavuzturk, Assessment of the viability of hybrid geothermal heat pump systems with solar thermal collectors, ASHRAE Transactions

109 (2) (2003) 487-500.

[3] L. Lamarche, B. Beauchamp, New solutions for the short-time analysis of geothermal vertical boreholes, International Journal of Heat and Mass Transfer 50 (2007) 1408-1419. 
[4] C. Yavuzturk, J.D. Spitler, S. J. Rees, A Transient Two-Dimensional Finite Volume Model for the Simulation of Vertical U-Tube Ground Heat Exchangers, ASHRAE Transactions 105 (2) (1999) 465-474.

[5] P. Cui, H. Yang, Z. Fang, Numerical analysis and experimental validation of heat transfer in ground heat exchangers in alternative operation modes, Energy and Buildings 40 (6) (2007) 1060-1066.

[6] L.R. Ingersoll, O.J. Zobel, A.C. Ingersoll, Heat Conduction with Engineering, Geological, and Other Applications, McGraw-Hill, New York,1954.

[7] S.A. Marshall, An approximate method for reducing the order of a linear system, Control 10 (1966) 642-643.

[8] A.M. Mokhtari, Etude du comportement thermique des bâtiments en contact avec le sol par l'analyse modale, Thèse, INSA de Lyon, 1988.

[9] Y. Gao, J.J. Roux, L.H. Zhao, Y. Jiang, Dynamical building simulation: A low order model for thermal bridges losses, Energy and Buildings 40 (12) (2008) 2236-2243

[10] D. Petit. Réduction de modèles de connaissance et identification de modèles d'ordre réduit, Ph.D. dissertation, Université de Provence (Aix-Marseille I), France, 1991.

[11] G.P. Michaïlesco. Approximation des systèmes complexes par des modèles de dimension réduite. Thèse d'Etat, Centre d'Orsay, Université de Paris-sud, 1979.

[12] B.C. Moore, Principal component analysis in linear system: controllability, observability, and model reduction, IEEE Transactions on Automatic Control AC 26 (1) (1981) 17-32.

[13] S.P. Rottmayer, W.A. Beckman, J.W. Mitchell, Simulation of a Single Vertical U-Tube Ground Heat Exchanger in an Infinite Medium, ASHRAE Transactions 103 (2) (1997) 651659

[14] Z. Li, M. Zheng, Development of a numerical model for the simulation of vertical U-tube ground heat exchangers, Applied Thermal Engineering 29 (2009) 920-924 
[15] http://www.geuz.org/gmsh/

[16] I. Demirdžić, S. Muzaferija, Numerical method for coupled fluid flow, heat transfer and stress analysis using unstructured moving meshes with cells of arbitrary topology, Computer Methods in Applied Mechanics and Engineering 125 (1995) 235-255.

[17] P. Eskilson, Thermal analysis of heat extraction boreholes, Doctoral Thesis, Department of Mathematical Physics, University of Lund, Lund, Sweden, 1987. 
Table 1. Simulation parameters

\begin{tabular}{|l|l|l|}
\hline Parameters & Unit & value \\
\hline Borehole radius & $\mathrm{m}$ & 0.055 \\
\hline External U pipe radius & $\mathrm{m}$ & 0.016 \\
\hline U pipe distance (centre to centre) & $\mathrm{m}$ & 0.06 \\
\hline Pipe number in a borehole & & 2 \\
\hline Soil conductivity & $\mathrm{W} / \mathrm{m}^{\circ} \mathrm{C}$ & 3.5 \\
\hline Grout conductivity & $\mathrm{W} / \mathrm{m}^{\circ} \mathrm{C}$ & 1.3 \\
\hline Soil diffusivity & $\mathrm{m}^{2} / \mathrm{s}$ & $1.62 \times 10^{-6}$ \\
\hline Grout diffusivity & $\mathrm{m}^{2} / \mathrm{s}$ & $3.33 \times 10^{-7}$ \\
\hline Basic time step & $\mathrm{hr}$ & 1 \\
\hline Error criterion for iteration & $\%$ & $10^{-4}$ \\
\hline
\end{tabular}


Table 2. Boundary conditions

\begin{tabular}{|l|l|l|}
\hline Boundaries & Unit & Value \\
\hline Initial soil temperature & ${ }^{\circ} \mathrm{C}$ & 10 \\
\hline Far field temperature & ${ }^{\circ} \mathrm{C}$ & 10 \\
\hline Constant flux density in each pipe & $\mathrm{W} / \mathrm{m}^{2}$ & 300 \\
\hline Sinusoidal flux density in each pipe & $\mathrm{W} / \mathrm{m}^{2}$ & $200+100 \sin (2 \pi \mathrm{t} / 24 \mathrm{hr})$ \\
\hline
\end{tabular}


Table 3. Mesh information used for the slice model

\begin{tabular}{|l|l|l|}
\hline Mesh information & Unit & Value \\
\hline Total nodes number & & 1018 \\
\hline $\begin{array}{l}\text { Nodes number in 4 sub-zone models } \\
\text { (from the borehole zone to the exterior zone) }\end{array}$ & & $474 / 140 / 203 / 201$ \\
\hline Average mesh size & $\mathrm{m}^{2}$ & $1.5798 \times 10$ \\
\hline Maximum mesh size & $\mathrm{m}^{2}$ & $3.1906 \times 10^{2}$ \\
\hline Minimum mesh size & $\mathrm{m}^{2}$ & $4.1557 \times 10^{-6}$ \\
\hline
\end{tabular}




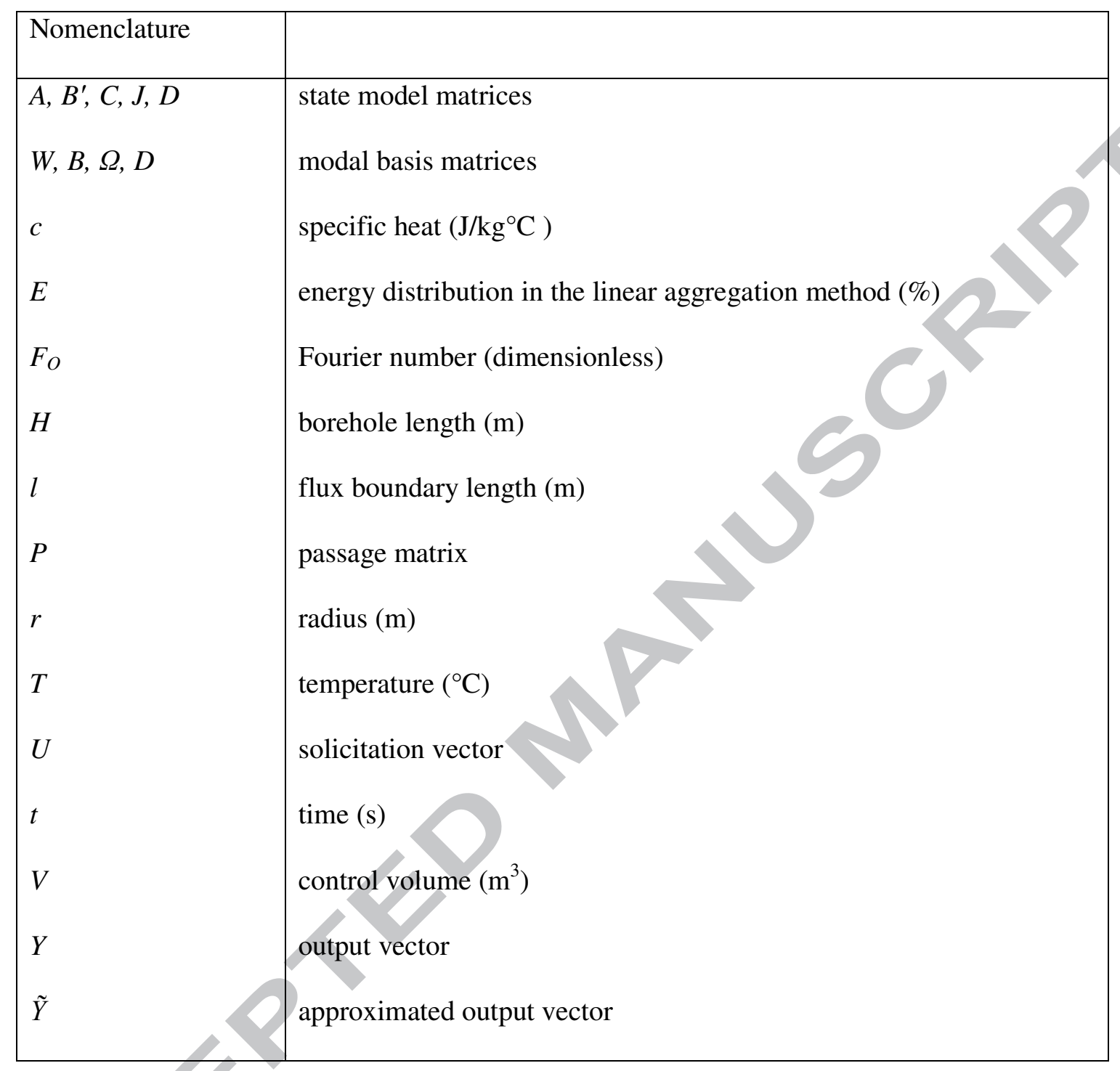

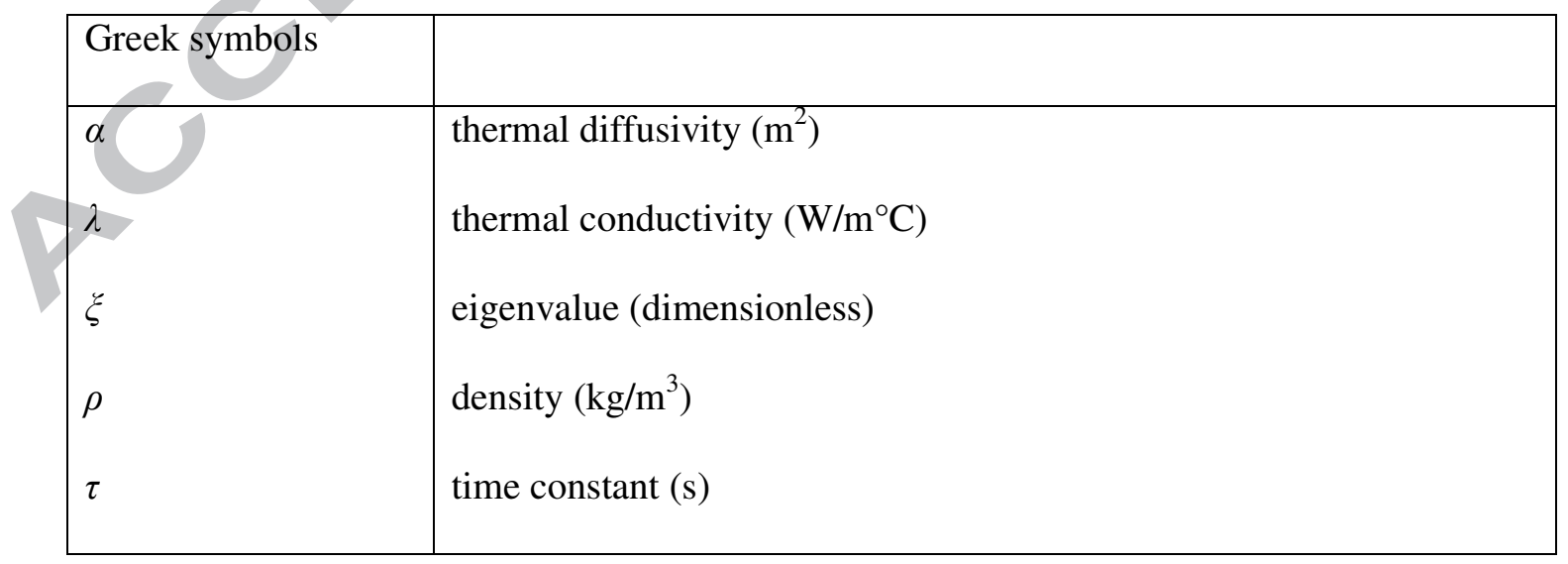




\begin{tabular}{|c|c|}
\hline Subscripts & \\
\hline $\mathrm{b}$ & borehole heat exchanger \\
\hline $\mathrm{e}$ & element in the finite elements method \\
\hline $\mathrm{m}$ & reduced order \\
\hline $\mathrm{n}$ & complete order \\
\hline $\mathrm{p}$ & number of solicitation \\
\hline q & number of observation \\
\hline ref & reference model \\
\hline test & test model \\
\hline 0 & initial heat transfer model prior to approximation \\
\hline $1,2,3$ & node order in a triangulation element \\
\hline
\end{tabular}




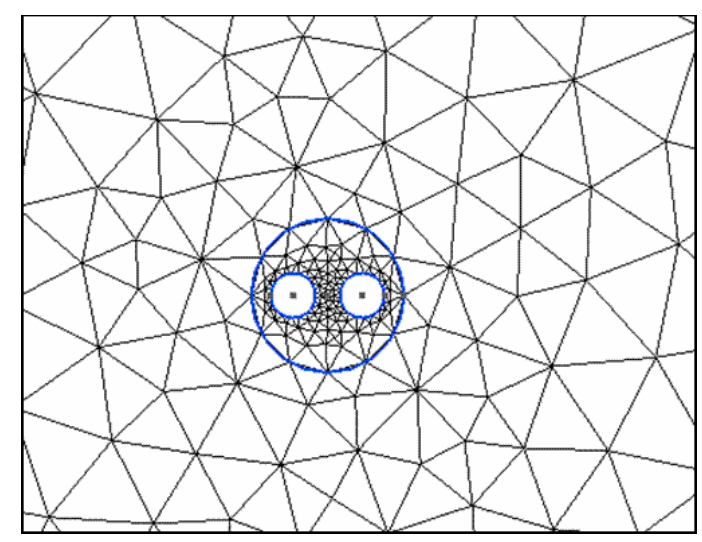

Figure 1. Example of the Delaunay triangular mesh by Gmsh 


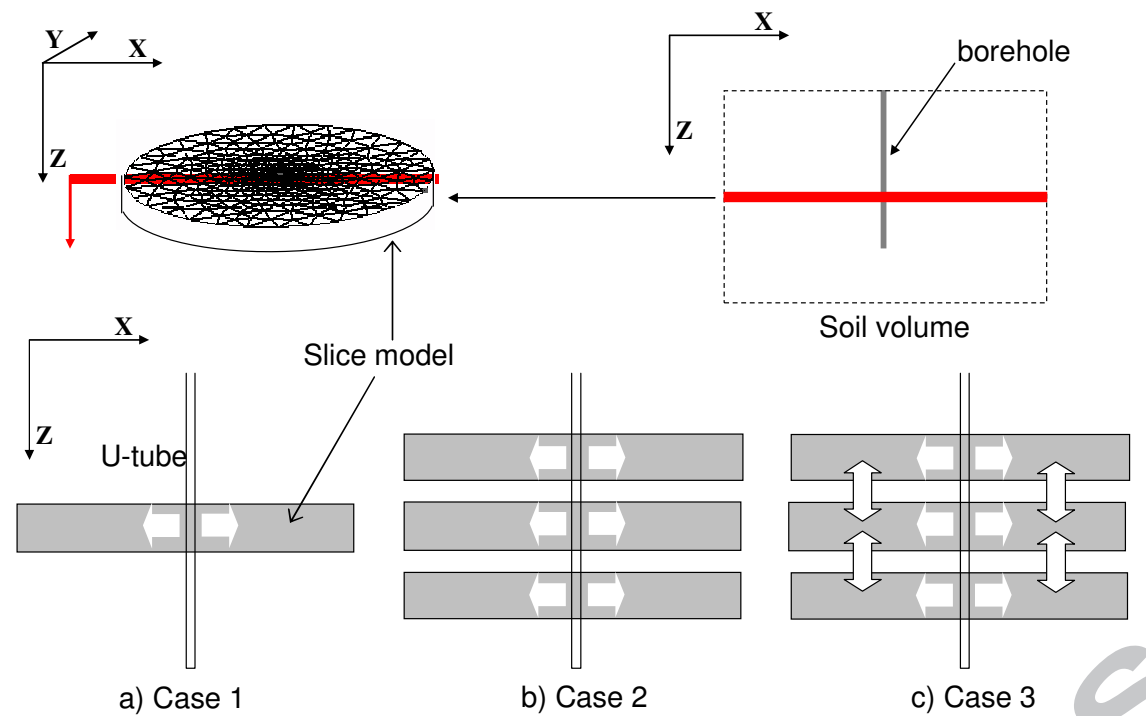

Figure 2. Slice model in the 3 different cases (2D, Quasi 3D, and 3D) 


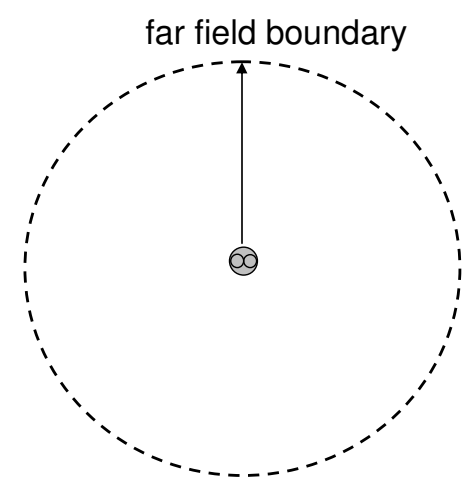

a) Slice model

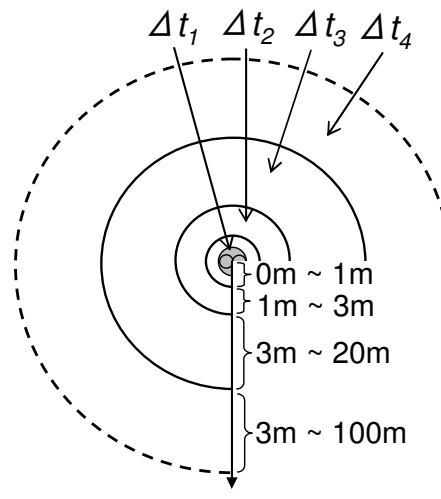

b) sub-zone models

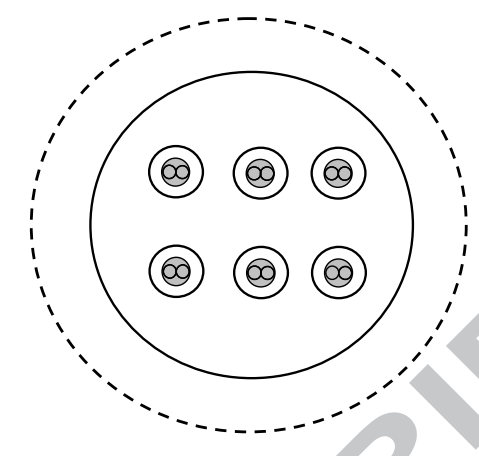

c) sub-zone models in multiple boreholes

Figure 3. Decomposition of a slice model by Sub-zone models 


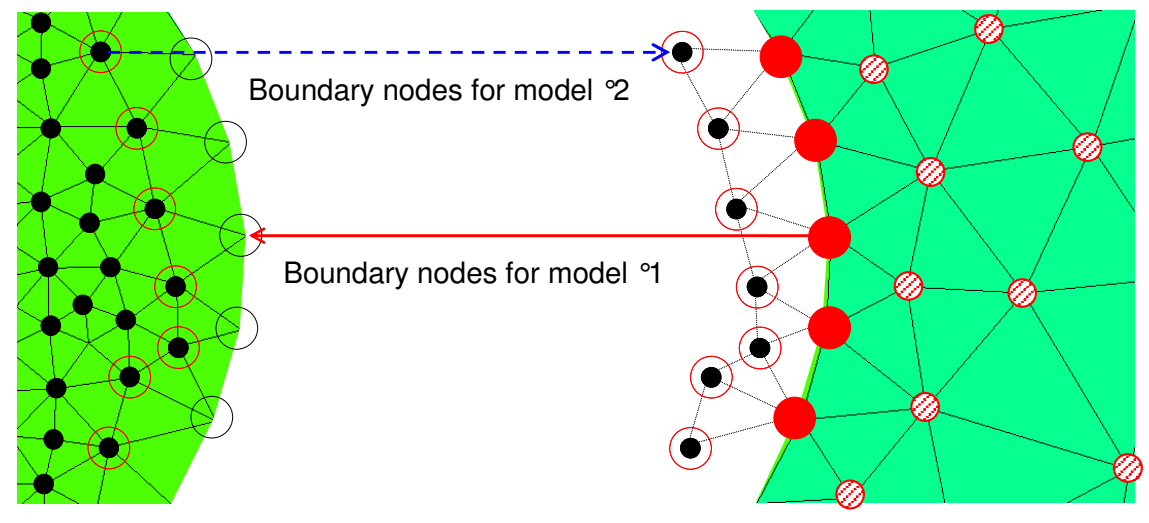

Sub-zone Model ${ }^{\circ} 1$

Sub-zone model ${ }^{\circ} 2$

Figure 4. New boundary for coupling sub-zone models in FEM 


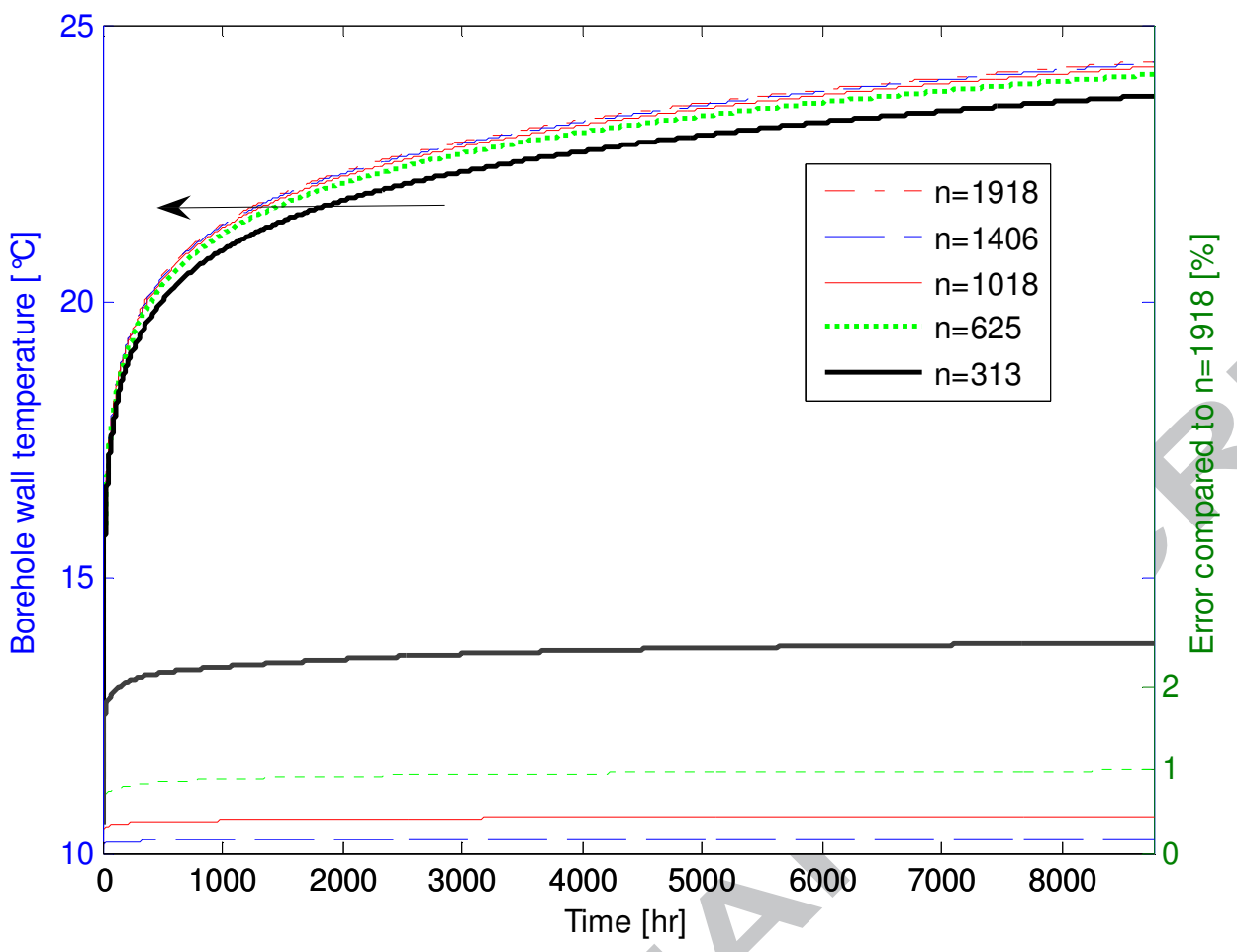

Figure 5. Comparison of temperature evolution and error estimation according to mesh resolution 

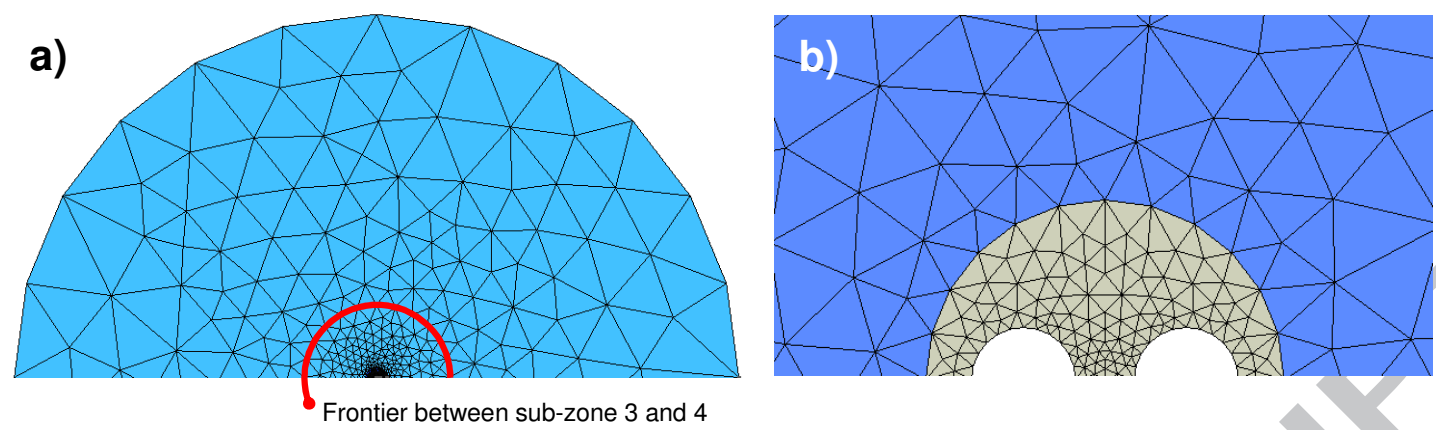

Figure 6. a) Mesh for soil domain $(n=1028)$ and $b)$ magnification of the mesh near the U-tube 


\section{ACCEPTED MANUSCRIPT}

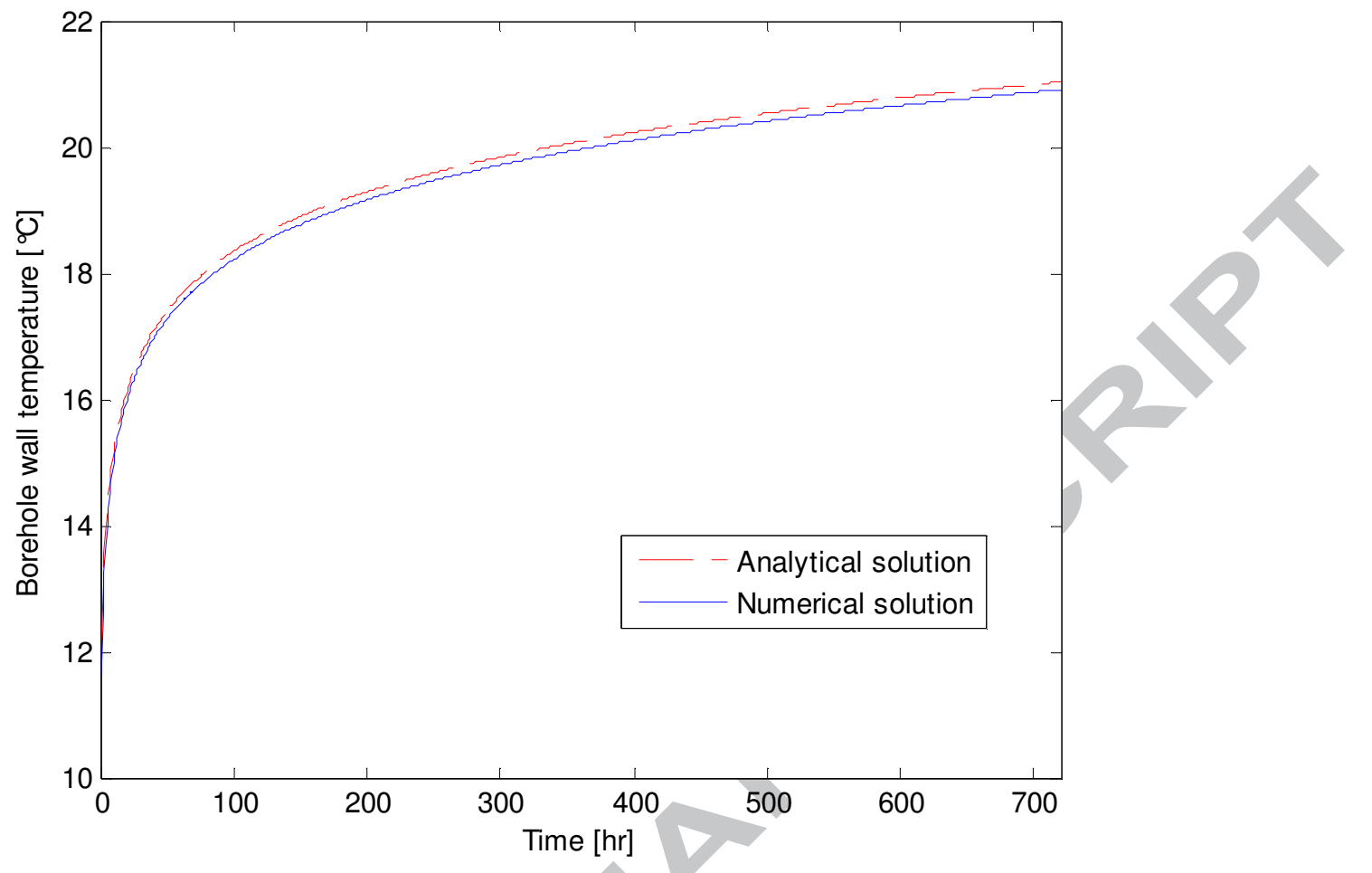

Figure 7. Borehole wall temperature comparison between the numerical and analytical solutions 


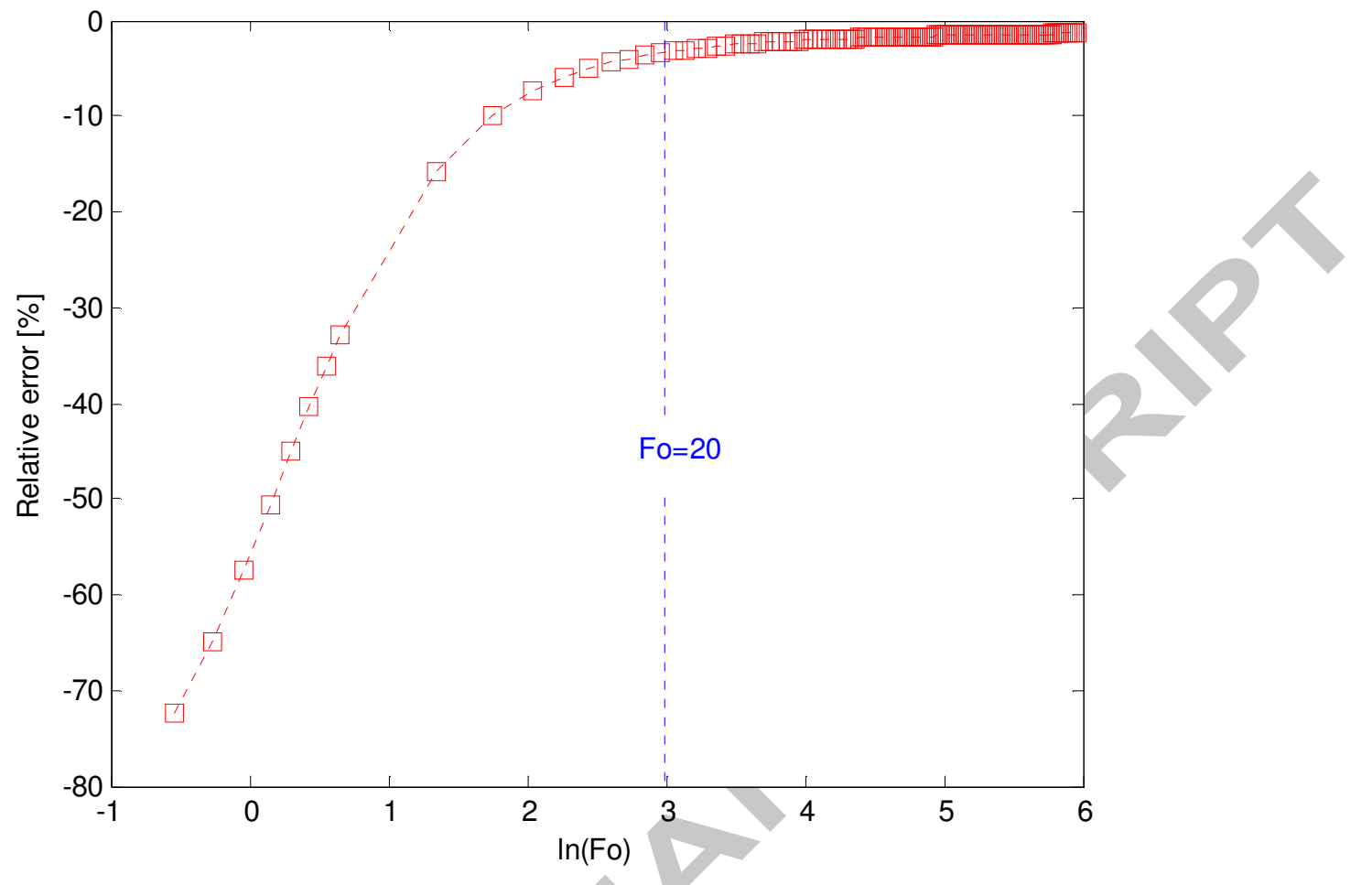

Figure 8. Relative error estimation between the numerical and analytical results 


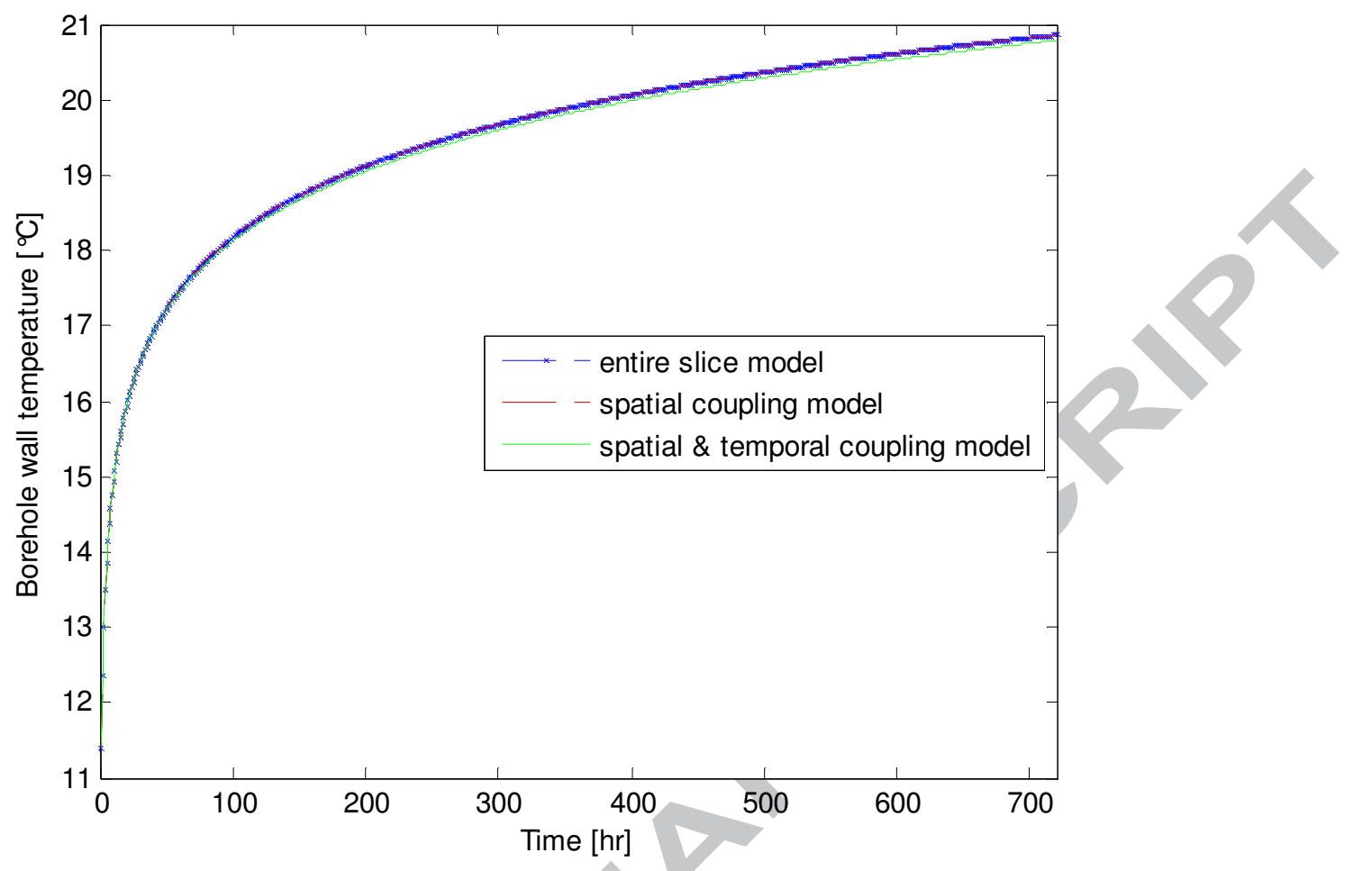

Figure 9. Spatial and temporal coupling validation in sub-zone structured model 


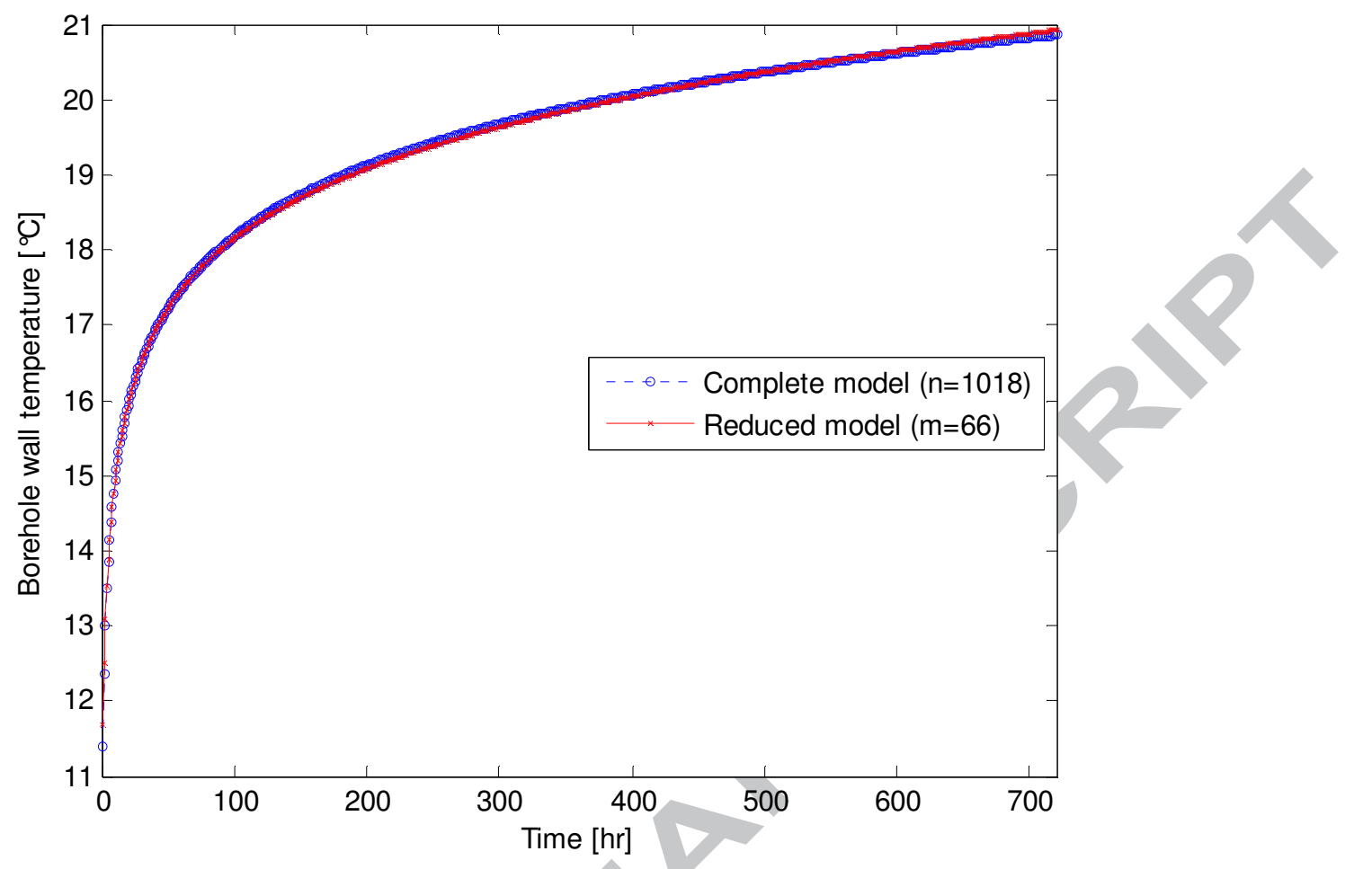

Figure 10. Reduced model (LA) results compared to the sub-zone complete model 

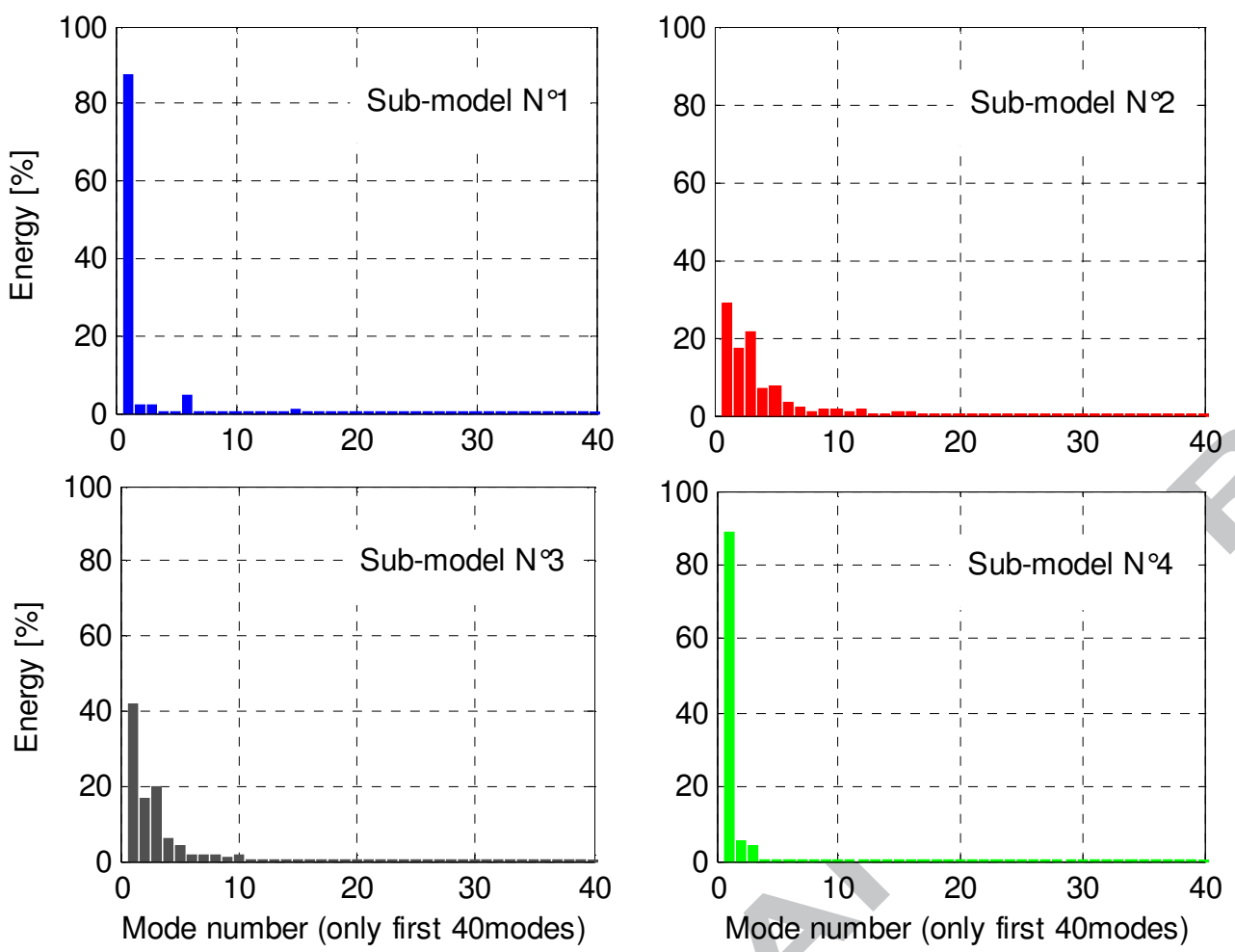

Figure 11. Energy distribution (LA method) for each sub zone model 


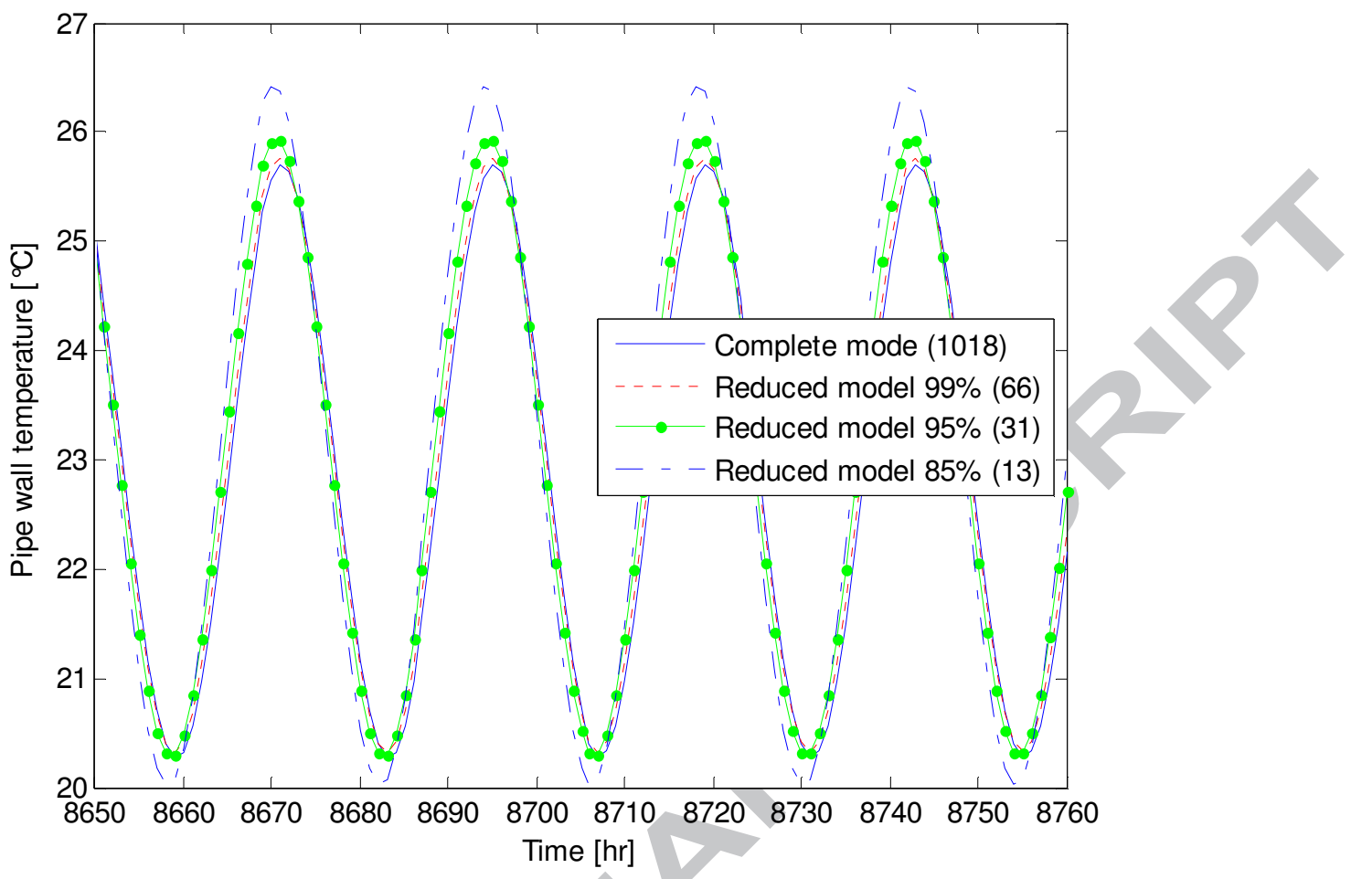

Figure 12. Results on using various energy criteria in LA reduced model 


\section{ACCEPTED MANUSCRIPT}

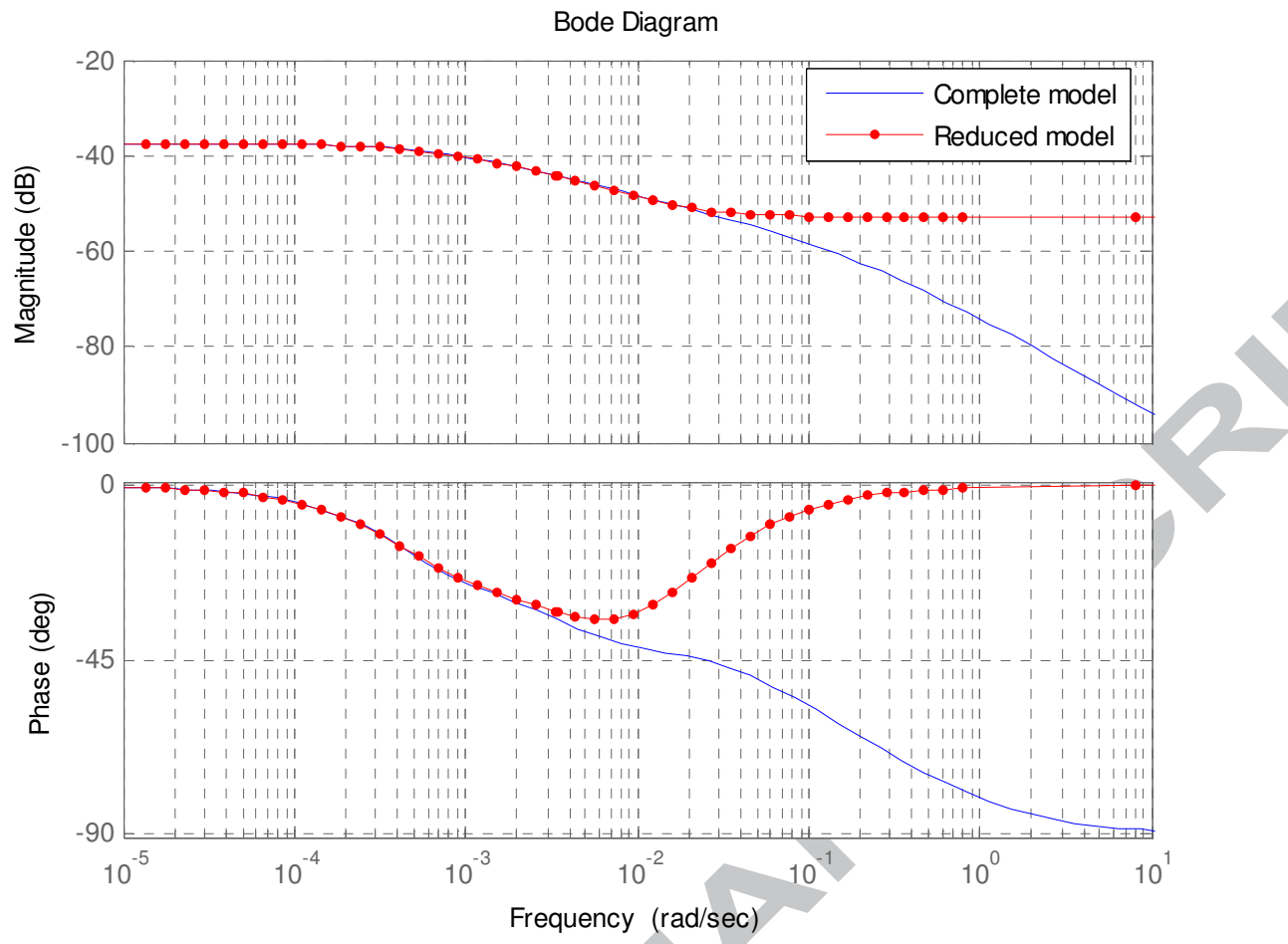

Figure 13. Bode diagrams of full-order model and low-order model in the borehole region 